\title{
Efficacy of embryo transfer in lactating dairy cows during summer using fresh or vitrified embryos produced in vitro with sex-sorted semen
}

\author{
B. M. Stewart, ${ }^{\star}$ J. Block, $\dagger \S^{1}$ P. Morelli, ${ }^{\star}$ A. E. Navarette,‡ M. Amstalden,‡ L. Bonilla, $\S^{1}$ P. J. Hansen, $\S^{1}$ \\ and T. R. Bilby* $\ddagger^{2}$ \\ *Texas AgriLife Research and Extension, Texas A\&M System, Stephenville 76401 \\ †OvaTech LLC, Gainesville, FL 32605 \\ fDepartment of Animal Sciences, Texas A\&M University, College Station 77843 \\ §Department of Animal Sciences, University of Florida, Gainesville 32611-0910
}

\section{ABSTRACT}

The objective was to determine whether transfer of fresh or vitrified embryos produced in vitro with sexsorted semen improves pregnancy and calving rates during summer in lactating dairy cows compared with artificial insemination (AI). Lactating dairy cows ( $\mathrm{n}=$ 722 ) were enrolled during summer months at 2 commercial dairies in Central Texas and randomly assigned to 1 of 3 treatments: AI with conventional semen (n $=227$ ), embryo transfer-vitrified $(\mathrm{ET}-\mathrm{V} ; \mathrm{n}=279)$ or embryo transfer-fresh (ET-F; $\mathrm{n}=216)$. Embryos were produced in vitro using sex-sorted semen and with Block-Bonilla-Hansen-7 culture medium. For vitrification, grade 1 expanded blastocysts were harvested on d 7 after fertilization and vitrified using the open-pulled straw method. Fresh embryos were grade 1 blastocysts and expanded blastocysts harvested on d 7 after fertilization. Cows were submitted to the Ovsynch56 protocol: $\mathrm{d}-10 \mathrm{GnRH}, \mathrm{d}-3 \mathrm{PGF}_{2 \alpha}, \mathrm{d}-1 \mathrm{GnRH}$ and d 0 timed AI; or Select Synch protocol: d -9 GnRH, $\mathrm{d}-2 \mathrm{PGF}_{2 \alpha}$, and $\mathrm{AI}$ following detected estrus (day of $\mathrm{AI}=\mathrm{d} 0$ ). On d 7 , all cows were examined for presence of a corpus luteum (CL). A vitrified or fresh embryo was transferred to cows with CL in ET-V and ET-F groups. Cows were considered synchronized if progesterone was $<1 \mathrm{ng} / \mathrm{mL}$ on $\mathrm{d} 0$ and a CL was present on d 7 . At d $40 \pm 7$ of gestation, the percentage of cows pregnant was greater for the ET-F compared with the ET-V and AI groups among all cows (42.1 vs. 29.3 and $18.3 \%$, respectively) and synchronized cows (45.5 vs. 31.6 and $24.8 \%$, respectively). Also, the percentage of cows pregnant was greater for the ET-V than

\footnotetext{
Received November 14, 2010.

Accepted March 7, 2011.

${ }^{1}$ Conflict of interest statement: J. Block, L. Bonilla, and P. J. Hansen have an ownership position in Cooley Biotech LLC, the licensee of BBH7 medium.

${ }^{2}$ Corresponding author: trbilby@ag.tamu.edu
}

the AI group among all cows and tended to be greater among synchronized cows. At d $97 \pm 7$ of gestation, the percentage of cows pregnant among all cows was greater for ET-F and ET-V groups than for the AI group (36.4 and 25.7 vs. $17.0 \%$, respectively) and the percentage for the ET-F group was greater than for the ET-V group. Among synchronized cows, the percentage of cows pregnant was significantly increased for the ET-F group than for ET-V and AI groups (39.4 vs. 27.8 and $23.1 \%$, respectively) and no difference was found between ET-V and AI groups. No effect of treatment on embryo loss was observed. The percentage of cows with live births was significantly increased for the ET-F than for ET-V and AI groups among all cows (27.5 vs. 17.1 and $14.6 \%$, respectively) and synchronized cows (29.9 vs. 18.5 and $20.0 \%$, respectively). The percentage of cows giving birth to a live heifer was significantly increased for the ET-F and ET-V groups compared with the AI group among all cows (79.1 and 72.5 vs. $50.0 \%$, respectively) and synchronized cows (79.1 and 72.5 vs. $50.0 \%$, respectively). No difference existed between ET-F and ET-V groups for percent live heifer births but both were greater than for the AI group. The transfer of fresh embryos produced in vitro using sex-sorted semen to lactating dairy cows during summer can effectively increase the percentage of cows that establish pregnancy and also the percentage of cows that give birth to a live heifer compared with percentages from AI with conventional semen.

Key words: embryo transfer, sexed semen, heat stress, dairy cattle

\section{INTRODUCTION}

The effects of heat stress on reproductive function in lactating dairy cows are well known (Hansen, 1997; Wolfenson et al., 2000; Hansen, 2007). Heat stress is not confined to cows in warm climates because hyperthermia can occur in lactating cows at temperatures as low as 25 to $28^{\circ} \mathrm{C}$ (Berman et al., 1985; Sartori et al., 
2002) and decreased reproductive function during the summer has been reported in regions with temperate climates (Udomprasert and Williamson, 1987; Sartori et al., 2002; Ambrose et al., 2006). Moreover, the effects of heat stress on fertility are likely to increase (Hansen, 2007), given that increased milk production makes it more difficult to regulate body temperature during heat stress (Berman et al., 1985; Berman, 2005) and also exacerbates the effects of heat stress on fertility (Umphrey et al., 2001). Thus, strategies that mitigate the negative effects of heat stress on reproductive function are likely to become essential for continued improvement in reproductive efficiency of dairy cows.

One of the most effective strategies for improving fertility in lactating dairy cows exposed to heat stress is embryo transfer (ET; Ambrose et al., 1999; Al-Katanani et al., 2002; Demetrio et al., 2007). Despite the effectiveness of ET during the summer, use of this approach commercially has been limited. The high costs of embryo production by superovulation and transvaginal oocyte aspiration can be overcome through the use of abattoir-derived oocytes in conjunction with in vitro embryo production (IVP). However, decreased survival following cryopreservation (Al-Katanani et al., 2002; Lazzari et al., 2002; Rizos et al., 2002) and skewed male gender ratio (van Wagtendonk-de Leeuw et al., 1998; Hasler, 2000; Block and Hansen, 2007), limits the widespread application of IVP embryos in the commercial dairy industry.

Suboptimal embryo culture conditions are one reason for the decreased survival of bovine IVP embryos following cryopreservation (Lazzari et al., 2002; Rizos et al., 2002). Recently, it was reported that culture of embryos in a novel serum-free culture medium, Block-BonillaHansen-7 (BBH7), could improve survival following cryopreservation compared with embryos cultured in synthetic oviductal fluid (Block et al., 2010).

The use of sex-sorted semen for embryo production represents one strategy to overcome the male biased gender ratio typically observed for embryos produced in vitro. Xu and colleagues (2006) reported that pregnancy rates achieved in non-heat-stressed recipients following transfer of IVP embryos produced with sex-sorted semen were similar to those obtained with IVP embryos produced with non-sorted semen. To date, no study has evaluated the effectiveness of using IVP embryos produced with sex-sorted semen during the summer with heat-stressed, lactating recipients.

The objective was to determine whether transfer of vitrified and fresh embryos produced using sexed semen and following culture in BBH7 medium would improve pregnancy rates in lactating dairy cows during the summer compared with AI.

\section{MATERIALS AND METHODS}

\section{Materials}

All materials were purchased from Sigma (St. Louis, MO) or Fisher Scientific (Fairlawn, NJ), unless specified otherwise. The media in vitro fertilization (IVF)Tyrode's Lactate and Hepes-Tyrode's Lactate were purchased from Caisson Laboratories, Inc. (Logan, UT) and Millipore (Billerica, MA), respectively. These media were used to prepare IVF-Tyrode's Albumin Lactate Pyruvate (TALP) and Hepes-TALP as described previously (Parrish et al., 1986). The oocyte collection medium was Tissue Culture Medium-199 (TCM-199) with Hanks' salts without phenol red (Atlanta Biologicals, Norcross, GA) and supplemented with $2 \%$ (vol/ vol) bovine steer serum (Pel-Freez, Rogers, AR), 2 U of heparin $/ \mathrm{mL}, 100 \mathrm{U}$ of penicillin- $\mathrm{G} / \mathrm{mL}, 0.1 \mathrm{mg} /$ $\mathrm{mL}$ of streptomycin (Chemicon, Temecula, CA), and $1 \mathrm{~m} M$ glutamine. The oocyte maturation medium was TCM-199 (Invitrogen, Carlsbad, CA) with Earle's salts supplemented with $10 \%$ (vol/vol) bovine steer serum, 2 $\mu \mathrm{g}$ of estradiol $17-\beta / \mathrm{mL}, 20 \mu \mathrm{g} / \mathrm{mL}$ of bovine FSH (Folltropin-V; Bioniche, Belleville, ON, Canada), $22 \mu \mathrm{g}$ of sodium pyruvate $/ \mathrm{mL}, 50 \mu \mathrm{g}$ of gentamicin sulfate $/ \mathrm{mL}$, and $1 \mathrm{~m} M$ glutamine. Percoll was from GE Health Care (Waukesha, WI). The medium BBH7 is a proprietary, serum-free culture medium developed by the University of Florida and licensed to Cooley Biotech (Gainesville, FL). For the present study, BBH7 was prepared at the University of Florida. Gonadotropin-releasing hormone (2 mL i.m.; Cystorelin; Merial, Duluth, GA) and $\mathrm{PGF}_{2 \alpha}$ (5 mL i.m.; Lutalyse; Pfizer, New York, NY) were used for synchronization of estrous and lidocaine ( $2 \%$ wt/vol; Sparhawk Laboratories, Inc., Lenexa, KS) was used as a local anesthetic before embryo transfer.

\section{Animals}

The experiment was conducted on 2 commercial dairies in North Central Texas between July and October 2009. Data were obtained from a nearby weather station in North Central Texas and recorded by the Weather Underground (http://www.wunderground. com). Values obtained from the weather station were used to calculate temperature-humidity index (THI), using the equation THI $=\left(9 / 5\right.$ temperature $\left.{ }^{\circ} \mathrm{C}\right)-(0.55$ $-0.0055 \times$ humidity $) \times\left(9 / 5\right.$ temperature $\left.{ }^{\circ} \mathrm{C}-26.8\right)$, described by (NRC, 1971; Dikmen and Hansen, 2009). The maximum daily temperature and average relative humidity from July 9 through October 18, 2009 (from $10 \mathrm{~d}$ before experiment was initiated until $10 \mathrm{~d}$ after the last ET) was used to calculate the THI, as shown in Figure 1. 


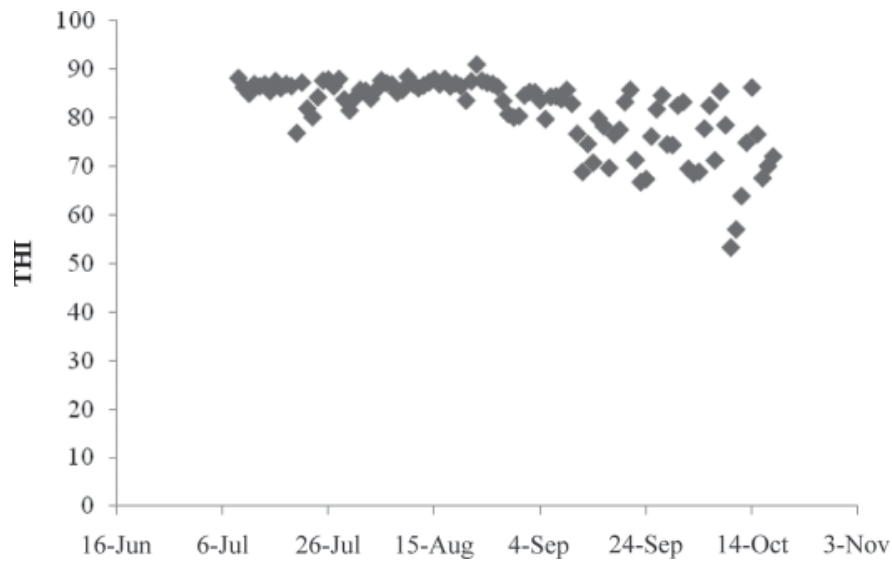

Figure 1. Temperature humidity index (THI) values for farm 1 and farm 2 from July 9 to October 18, 2009.

At farm 1, primiparous and multiparous lactating Holstein cows that had not been detected in estrus ( $\mathrm{n}$ $=467)$ were enrolled in the experiment on $\mathrm{d} 0$ after being synchronized using the Ovsynch-56 protocol (d $-10 \mathrm{GnRH}, \mathrm{d}-3 \mathrm{PGF}_{2 \alpha}$, d $-1 \mathrm{GnRH}$; Brusveen et al., 2009). Cows were randomly assigned by lactation number, number of previous AI or ET and projected 305-d milk yield to 1 of 3 treatment groups: AI [n = 153; both timed AI (TAI) and AI at detected estrus], embryo transfer with fresh embryos $(\mathbf{E T}-\mathbf{F} ; \mathrm{n}=136)$ or embryo transfer with vitrified embryos (ET-V; n $=178$ ). Eleven replicates were completed at farm 1 . At farm 2, primiparous and multiparous lactating Holstein, Jersey, and Holstein $\times$ Jersey cows $(\mathrm{n}=255)$ that had not been detected in estrus were enrolled in the experiment on d 0 after being synchronized using the Select Synch protocol (d -9 GnRH, d $-2 \mathrm{PGF}_{2 \alpha}$, and AI at detected estrus (d 0); Stevenson et al., 1999). Cows were observed for signs of estrus (removal of tail chalk and visual observation of standing estrus) in the morning at $\mathrm{d} 2$ and $\mathrm{d} 3$ after $\mathrm{PGF}_{2 \alpha}$ injection. Cows that exhibited estrus behavior $2 \mathrm{~d}$ after $\mathrm{PGF}_{2 \alpha}$ injection were assigned to the AI group $(\mathrm{n}=74)$, whereas cows that exhibited estrus behavior $3 \mathrm{~d}$ following $\mathrm{PGF}_{2 \alpha}$ injection were randomly assigned as described for farm 1 to either the ET-F $(\mathrm{n}=80)$ or ET-V $(\mathrm{n}=101)$ treatment groups. The decision to assign cows to treatment in this way was due to logistical constraints at farm 2 and with production and transfer of embryos on 2 consecutive days. Seven replicates were completed at farm 2. The number of previous AI or ET ranged from 0 to 12 , with most the cows $(\mathrm{n}=527)$ having less than 3 AI or ET. Throughout the manuscript, AI is used to refer to the control treatment group, which consists of both TAI cows from farm 1 and AI cows at detected estrus in farm 2.
Cows at both locations were housed in freestall barns with grooved concrete floors equipped with soakers and fans. The soakers were placed above the headlocks and in the holding pen and were programmed to operate intermittently at dry bulb temperatures of $24^{\circ} \mathrm{C}$ or higher. The fans were placed above the headlocks, freestalls, and in the holding pen and ran continuously beginning at $24^{\circ} \mathrm{C}$. All cows were fed a TMR twice daily and milked 3 times daily.

Cows assigned to the AI group at farm 1 were inseminated at approximately 16 to $20 \mathrm{~h}$ after the second GnRH injection of the OvSynch-56 protocol. At farm 2 , cows assigned to the AI group were inseminated at detected estrus. At both farms, cows were inseminated by on-farm technicians with conventional semen from one of multiple Holstein bulls. On d 7, the presence or absence of a corpus luteum (CL) was confirmed for all cows, including those assigned to the AI group, by ultrasonography, using an Ibex portable ultrasound (E.I. Medical Imaging, Loveland, CO). All cows were also evaluated for BCS ( $1=$ emaciated, $5=$ obese $)$, as described by Ferguson et al. (1994). Cows assigned to the ET-F and ET-V groups, with a CL, received epidural anesthesia ( $5 \mathrm{~mL}$ of $2 \%$ lidocaine, wt/vol) and a single embryo was transferred to the uterine horn ipsilateral to the ovary with a CL using the transcervical method. All embryos were transferred by a single experienced technician. Pregnancy was diagnosed by rectal palpation by each farm's veterinarian at d $40 \pm 7$ and d 97 \pm 7 of gestation. Calving data, including whether the calf was born alive and calf gender, were recorded at each farm.

\section{Blood Sampling and Progesterone Analysis}

Blood samples were collected on d 0 by coccygeal venipuncture into sterile Vacutainer tubes (K2 EDTA; Becton Dickinson, Franklin Lakes, NJ), labeled by cow number and placed on ice. Blood samples were centrifuged $\left(2000 \times g\right.$ for $15 \mathrm{~min}$ at $\left.4^{\circ} \mathrm{C}\right)$ upon returning to the laboratory approximately 3 to $5 \mathrm{~h}$ later. Plasma was separated and stored at $-20^{\circ} \mathrm{C}$ until assayed for plasma progesterone $\left(\mathbf{P}_{4}\right)$ using a direct solid-phase, no-extraction RIA (Coat-a-Count Progesterone, DPC; Diagnostic Products Corporation, Los Angeles, CA). The intra- and interassay coefficients of variation were 5.4 and $9.5 \%$, respectively. Plasma progesterone concentration was used to determine cyclicity and estrus synchronization. Cows with $\mathrm{P}_{4}$ concentrations $<1 \mathrm{ng} /$ $\mathrm{mL}$ were considered to be without a functional CL and cows with $\mathrm{P}_{4} \geq 1 \mathrm{ng} / \mathrm{mL}$ were considered to have a functional CL. To determine the percentage of cows enrolled at each farm that were synchronized, cows were classified into 2 categories according to plasma $\mathrm{P}_{4}$ 
concentration on d 0 and presence or absence of a CL on $\mathrm{d}$ 7. An estrous cycle was classified as synchronized if $\mathrm{P}_{4}$ was $<1 \mathrm{ng} / \mathrm{mL}$ on $\mathrm{d} 0$ and had presence of a CL on $\mathrm{d} 7$. An estrous cycle was non-synchronized if $\mathrm{P}_{4}$ was $>1 \mathrm{ng} / \mathrm{mL}$ on $\mathrm{d} 0$ and had presence or absence of a CL on $\mathrm{d} 7$ or if $\mathrm{P}_{4}$ was $<1 \mathrm{ng} / \mathrm{mL}$ on $\mathrm{d} 0$ and the CL was absent on $\mathrm{d} 7$.

\section{In Vitro Embryo Production}

All procedures related to in vitro embryo production were performed as described previously (Block et al., 2010) unless noted otherwise. Cumulus oocyte complexes (COC) were collected from abattoir-derived ovaries of Holstein cows (ABF Packing, Dublin, TX). Following in vitro maturation, $\mathrm{COC}$ were fertilized in vitro with X-sorted semen from 1 of 4 different Holstein bulls (Genex Cooperative, Inc., Shawano, WI). Prior to fertilization, COC were washed once in Hepes-TALP and then placed in groups of 30 into $50-\mu \mathrm{L}$ microdrops of IVF-TALP that contained $2 \mathrm{~m} M$ caffeine. For sperm preparation, semen was layered on top of a mini-Percoll gradient $(300 \mu \mathrm{L}$ of $45 \%$ Percoll over $300 \mu \mathrm{L}$ of $90 \%$ Percoll; GE Healthcare, Chalfont St. Giles, UK) and then centrifuged at $600 \times g$ for $10 \mathrm{~min}$. The sperm pellet was placed into a 2 -mL microcentrifuge tube containing $1 \mathrm{~mL}$ of Hepes-TALP modified to contain 10 $\mathrm{m} M$ caffeine and then centrifuged for $5 \mathrm{~min}$ at $300 \times g$. Following centrifugation, the supernatant was removed and the sperm pellet was diluted in IVF-TALP containing $2 \mathrm{~m} M$ caffeine. After sperm dilution, $20 \mu \mathrm{L}$ of the sperm solution and $3 \mu \mathrm{L}$ of $0.5 \mathrm{mM}$ penicillamine, $0.25 \mathrm{~m} M$ hypotaurine, and $25 \mu M$ epinephrine in $0.9 \%$ (wt/vol) $\mathrm{NaCl}$ were added to each fertilization drop. The final sperm concentration was $1 \times 10^{6} \mathrm{sperm} / \mathrm{mL}$. Spermatozoa and COC were co-incubated for $8 \mathrm{~h}$. Following fertilization, presumptive zygotes were cultured in 50- $\mu \mathrm{L}$ microdrops of BBH7 overlaid with mineral oil in groups of 25 to 30 in a humidified atmosphere of $5 \%$ $\mathrm{CO}_{2}, 5 \% \mathrm{O}_{2}$, and $90 \% \mathrm{~N}_{2}$ at $38.5^{\circ} \mathrm{C}$ in a modular chamber (Billups-Rothenberg, Inc., Del Mar, CA) for $7 \mathrm{~d}$.

For fresh embryos, grade 1 blastocysts and expanded blastocysts (Robertson and Nelson, 1998) were harvested at $\mathrm{d} 7$ after insemination and loaded into $0.25-\mathrm{mL}$ straws in transfer medium (Hepes-TALP containing 10\% fetal bovine serum and $50 \mu M$ dithiothreitol). Straws were then placed into a portable incubator (Biotherm INC-12v; CryoLogic, Victoria, Australia) set at $38.5^{\circ} \mathrm{C}$ and transported to the farm for transfer to recipients. For vitrified embryos, grade 1 expanded blastocysts (Robertson and Nelson, 1998) were harvested at d 7 after fertilization and vitrified using the open-pulled straw method (Vajta et al., 1998). All steps were carried out with medium maintained on a warmed stage set at $39^{\circ} \mathrm{C}$. Harvested embryos were washed twice in holding medium [TCM-199 with Hank's salts supplemented with $10 \%$ (vol/vol) fetal bovine serum]. Embryos were then incubated in holding medium containing $7.5 \%$ (vol/vol) ethylene glycol and 7.5\% (vol/vol) dimethyl sulfoxide for $3 \mathrm{~min}$. Embryos were then moved to a solution of holding medium containing $16.5 \%$ (vol/vol) ethylene glycol and $16.5 \%$ (vol/vol) dimethyl sulfoxide and loaded into open-pulled straws. After $25 \mathrm{~s}$, the open-pulled straws were plunged directly into liquid nitrogen. Vitrified embryos were then stored in a liquid nitrogen tank until the day of transfer.

At the farms, vitrified embryos were warmed as described previously (Vajta et al., 1998). All steps were carried out with medium kept on a warmed stage set at $39^{\circ} \mathrm{C}$. Briefly, open-pulled straws were immersed into holding medium plus $0.3 \mathrm{M}$ sucrose and the embryos were expelled from the straws. Embryos were then immediately moved to another solution of holding medium plus $0.3 \mathrm{M}$ sucrose and held for $5 \mathrm{~min}$. Embryos were subsequently washed in holding medium plus 0.2 $M$ sucrose and holding medium alone for $5 \mathrm{~min}$ each and loaded into $0.25-\mathrm{mL}$ straws in transfer medium. Straws containing vitrified embryos were placed into a portable incubator set at $38.5^{\circ} \mathrm{C}$ and held until the time of transfer.

\section{Statistical Analysis}

Binomially distributed data were analyzed by logistic regression using the LOGISTIC procedure of SAS (Statistical Analysis Software 9.2; SAS Institute, 2008). All models included farm, treatment, week, BCS, parity (primiparous and multiparous), quartile of projected 305-d milk yield, number of previous AI or ET before enrollment, and their respective higher-order interactions. The final logistic regression model removed variables by a stepwise backward elimination based on the Wald statistics criterion when $P>0.10$. The percentage pregnant, percentage giving birth to a calf, live calf, heifer and live heifer, and pregnancy loss were analyzed among all cows (defined as cows that were inseminated or received an embryo) and also among the subset of cows that were considered to have their estrous cycles synchronized (defined as cows with $<$ 1ng of $\mathrm{P}_{4} / \mathrm{mL}$ on d 0 and the presence of a CL on d 7).

Continuous data were analyzed by ANOVA using the GLM procedure of SAS. Models included farm, treatment, BCS, parity (primiparous and multiparous), quartile of projected 305-d milk yield, number of previous AI or ET before enrollment and all higher order interactions. The parity, BCS, quartile of projected 305-d milk yield, and number of previous AI or ET before enrollment were initially included in the models, 
but if they had $P>0.10$, they were removed from the final analysis. Higher-order interactions were removed from the model if significance value was $P>0.10$. Least squares means were obtained for main effects of the model by using the LSMEANS procedure of SAS. For both logistic and GLM analyses, treatment mean probability differences were determined by contrasts (AI vs. ET-V, AI vs. ET-F, and ET-V vs. ET-F).

\section{RESULTS}

\section{Parity Distribution, Number of Previous Al or ET, DIM, BCS, Projected 305-d Milk Yield, and Synchronization Rate}

The percentage of primiparous cows enrolled $(\mathrm{AI}=$ $40.5 \%, \mathrm{ET}-\mathrm{V}=40.9 \%, \mathrm{ET}-F=37.0 \%)$ and the number of previous AI or ET at enrollment $(\mathrm{AI}=3.3 \pm 0.3$, $\mathrm{ET}-\mathrm{V}=3.2 \pm 0.2$, and ET- $F=3.2 \pm 0.2)$ did not differ among treatments. However, the percentage of primiparous cows enrolled and the number of previous AI or ET at enrollment were greater $(P<0.01)$ in farm 1 than in farm 2 (Table 1). Likewise, DIM (AI = $187 \pm 9, \mathrm{ET}-\mathrm{V}=176 \pm 9$, and ET- $F=180 \pm 9)$ and $\mathrm{BCS}$ recorded at d $7(\mathrm{AI}=2.76 \pm 0.02, \mathrm{ET}-\mathrm{V}=2.76$ \pm 0.02 , and $\mathrm{ET}-F=2.78 \pm 0.02)$ did not differ among treatments. However, DIM and BCS at d 7 were greater $(P<0.01)$ in farm 1 than in farm 2 (Table 1$)$. Although projected 305-d milk yield $(\mathrm{AI}=9,220 \pm 213$, ET-V $=9,299 \pm 204$, and ET- $F=9,473 \pm 207 \mathrm{~kg})$ did not differ among treatments, it was greater $(P<0.01)$ for multiparous than for primiparous cows $(8,443 \pm 206$ vs. $10,218 \pm 198 \mathrm{~kg}$ ) and greater in farm 2 than farm 1 (Table 1).

No difference was observed among treatments for the percentage of cow estrous cycles that were synchronized. However, the percentage of estrous cycles synchronized in farm 2 was greater $(P<0.01)$ than in farm 1 (Table 1 ). This was expected, because only those cows that were observed in estrus were enrolled at farm
2 , whereas all cows submitted to the synchronization protocol were enrolled at farm 1.

\section{Percent Pregnant and Pregnancy Loss}

At d $40 \pm 7$ of gestation, the percentage of cows pregnant was greater $(P<0.01)$ for the ET-F group compared with both ET-V and AI groups among all cows and among synchronized cows (Table 2). The percentage of cows pregnant was greater $(P=0.01)$ for the ET-V compared with the AI group among all cows and tended $(P=0.10)$ to be greater among synchronized cows (Table 2). The percentage of cows pregnant at $\mathrm{d}$ $40 \pm 7$ was greater $(P<0.01)$ at farm 2 than farm 1 for all cows (40.5 vs. $20.7 \%$ ) and synchronized cows (43.4 vs. $25.9 \%$ ) but no farm $\times$ treatment interaction existed.

At d $97 \pm 7$, the percentage of cows pregnant among all cows was greater $(P<0.05)$ for ET-F and ET-V groups compared with the AI group (Table 2). Among synchronized cows, the percentage of cows pregnant was greater $(P<0.05)$ for the ET-F group than for ET-V and AI groups (Table 2) and no difference was found between ET-V and AI groups (Table 2). The percentage of cows pregnant at d $97 \pm 7$ was greater $(P<0.01)$ at farm 2 than farm 1 for all cows $(37.4$ vs. $17.5 \%)$ and synchronized cows (40.0 vs. $21.9 \%)$ but no farm $\times$ treatment interaction existed.

No effect of treatment on pregnancy loss between d $40 \pm 7$ and calving among all cows or synchronized cows was observed (Table 2). In addition, no difference was found between treatment groups for pregnancy loss between d $40 \pm 7$ and d $97 \pm 7$ among all cows (AI = $5.1 \%, \mathrm{ET}-\mathrm{V}=8.8 \%$, and ET- $F=11.9 \%$ ) or synchronized cows $(\mathrm{AI}=5.7 \%, \mathrm{ET}-\mathrm{V}=9.1 \%, \mathrm{ET}-F=11.9 \%)$ and for pregnancy loss between $\mathrm{d} 97 \pm 7$ and calving among all cows $(\mathrm{AI}=6.1 \%, \mathrm{ET}-\mathrm{V}=18.4 \%$, and $\mathrm{ET}-\mathrm{F}$ $=8.5 \%)$ or synchronized cows $(\mathrm{AI}=6.9 \%, \mathrm{ET}-\mathrm{V}=$ $19.2 \%$, and $\mathrm{ET}-\mathrm{F}=8.5 \%)$. No farm $\times$ treatment interaction existed for pregnancy loss between d $40 \pm 7$ and d $97 \pm 7$ or between d $97 \pm 7$ and calving.

Table 1. Comparison of farms regarding percentage of primiparous cows enrolled, DIM, number of previous AI or embryo transfers, BCS, projected 305-d milk yield, and percentage of cows synchronized

\begin{tabular}{lccc}
\hline & \multicolumn{2}{c}{ Herd } \\
\cline { 2 - 3 } Item & Farm 1 & Farm 2 & P-value \\
\hline Cows enrolled $(\mathrm{n})$ & 467 & 255 & \\
Primiparous cows $(\%)$ & 34.1 & 49.8 & $<0.01$ \\
DIM at enrollment $( \pm$ SEM) & $212 \pm 8$ & $150 \pm 9$ & $<0.01$ \\
AI at enrollment $(\mathrm{n} ; \pm$ SEM) & $3.6 \pm 0.2$ & $2.9 \pm 0.3$ & $<0.01$ \\
BCS at enrollment $( \pm$ SEM) & $2.8 \pm 0.01$ & $2.7 \pm 0.02$ & $<0.01$ \\
Projected 305-d milk yield $(\mathrm{kg} ; \pm$ SEM) & $9,122 \pm 195$ & $9,539 \pm 210$ & $<0.01$ \\
Synchronized cows $(\%)$ & 62.9 & 82.5 & $<0.01$ \\
\hline
\end{tabular}


Table 2. Percentage of all cows and synchronized (Synch) cows pregnant at d $40 \pm 7$ and $97 \pm 7$ of gestation and pregnancy loss between d $40 \pm 7$ of gestation and calving following AI, timed embryo transfer of vitrified embryos (ET-V), or timed embryo transfer of fresh embryos (ET-F)

\begin{tabular}{|c|c|c|c|c|c|c|}
\hline \multirow[b]{2}{*}{ Treatment $^{1}$} & \multicolumn{2}{|c|}{$\begin{array}{l}\text { Pregnant cows at } \\
\quad \text { d } 40 \pm 7(\%)\end{array}$} & \multicolumn{2}{|c|}{$\begin{array}{l}\text { Pregnant cows at } \\
\quad \text { d } 97 \pm 7(\%)\end{array}$} & \multicolumn{2}{|c|}{$\begin{array}{c}\text { Pregnancy loss between } \\
\text { d } 40 \pm 7 \text { and calving (\%) }\end{array}$} \\
\hline & $\begin{array}{l}\text { All cows } \\
(\mathrm{n}=569)\end{array}$ & $\begin{array}{l}\text { Synch cows }^{2} \\
(\mathrm{n}=485)\end{array}$ & $\begin{array}{l}\text { All cows } \\
(\mathrm{n}=563)\end{array}$ & $\begin{array}{c}\text { Synch cows }^{2} \\
(\mathrm{n}=479)\end{array}$ & $\begin{array}{l}\text { All cows } \\
(\mathrm{n}=143)\end{array}$ & $\begin{array}{c}\text { Synch cows } \\
\\
(\mathrm{n}=143)\end{array}$ \\
\hline $\mathrm{AI}$ & $18.3^{\mathrm{a}}$ & $24.8^{\mathrm{a}}$ & $17.0^{\mathrm{a}}$ & $23.1^{\mathrm{a}}$ & 11.4 & 11.4 \\
\hline ET-V & $29.3^{\mathrm{b}}$ & $31.6^{\mathrm{a}}$ & $25.7^{\mathrm{b}}$ & $27.8^{\mathrm{a}}$ & 25.9 & 25.9 \\
\hline ET-F & $42.1^{\mathrm{c}}$ & $45.5^{\mathrm{b}}$ & $36.4^{\mathrm{c}}$ & $39.4^{\mathrm{b}}$ & 20.4 & 20.4 \\
\hline
\end{tabular}

${ }^{\mathrm{a}-c}$ Values within a column with different superscripts differ $(P \leq 0.05)$.

${ }^{1} \mathrm{AI}=$ either timed $\mathrm{AI}$ or AI at detected estrus with conventional semen following a synchronization protocol; ET-V $=$ embryo transfer of vitrified embryos produced in vitro with sex-sorted semen following a synchronization protocol; ET-F = embryo transfer of fresh embryos produced in vitro with sex-sorted semen following a synchronization protocol.

${ }^{2} \mathrm{~A}$ cow was considered to have a synchronized estrous cycle if progesterone concentration was $<1.0 \mathrm{ng} / \mathrm{mL}$ at anticipated ovulation (d 0) and a visible corpus luteum was present on $\mathrm{d} 7$.

\section{Gestation Length, Percent Calving, and Percent Heifers}

No difference $(P=0.88)$ between treatments for gestation lengths $(\mathrm{AI}=277 \pm 2 \mathrm{~d}$, ET-V $=277 \pm 2 \mathrm{~d}$, and ET- $F=276 \pm 2$ d) was observed.

The percentage of cows calving was greater $(P<$ 0.05) for the ET-F group than for AI and ET-V groups among all cows and synchronized cows (Table 3). Moreover, the percentage of cows giving birth to a live calf was also greater $(P<0.05)$ for the ET-F group than for $\mathrm{AI}$ and ET-V groups among all cows and synchronized cows (Table 3$)$. In addition, farm 2 had a greater $(P<$ $0.01)$ calving rate than farm 1 among all cows (27.7 vs. $13.4 \%$ ) and synchronized cows (29.7 vs. $16.8 \%$ ).

The percentage of calves born that were heifers were increased $(P<0.05)$ for both ET-F and ET-V groups compared with the AI group among all cows and synchronized cows (Table 3). No difference existed in the percentage of live calves that were heifers born between ET-F and ET-V groups among all cows and synchronized cows (Table 3 ). The percentage of live calves that were heifers were increased $(P<0.05)$ for ET-F and ET-V groups compared with the AI group among all cows and synchronized cows (Table 3). No difference existed in the percentage of live calves that were heifers between ET-F and ET-V groups among all cows and synchronized cows (Table 3 ).

\section{DISCUSSION}

Results indicate that the transfer of IVP embryos produced with sex-sorted semen can effectively improve fertility in lactating cows during the summer compared with AI and increase the percentage of cows giving birth to calves that are heifers. Results also indicate that culture of embryos in BBH7 does not enhance the cryotolerance of IVP embryos sufficiently to improve

Table 3. Percentage of all cows and synchronized (Synch) cows giving birth to a calf, a live calf, a heifer, and a live heifer following AI, timed embryo transfer of vitrified embryos (ET-V), or timed embryo transfer of fresh embryos (ET-F)

\begin{tabular}{|c|c|c|c|c|c|c|c|c|}
\hline Treatment $^{1}$ & \multicolumn{2}{|c|}{ Calves born (\%) } & \multicolumn{2}{|c|}{ Live calves born $(\%)$} & \multicolumn{2}{|c|}{ Heifers born ${ }^{2}(\%)$} & \multicolumn{2}{|c|}{ Live heifers born ${ }^{3}(\%)$} \\
\hline ET-V & $20.1^{\mathrm{a}}$ & $21.7^{\mathrm{a}}$ & $17.1^{\mathrm{a}}$ & $18.5^{\mathrm{a}}$ & $80.0^{\mathrm{b}}$ & $80.0^{\mathrm{b}}$ & $72.5^{\mathrm{b}}$ & $72.5^{\mathrm{b}}$ \\
\hline ET-F & $31.2^{\mathrm{b}}$ & $33.9^{\mathrm{b}}$ & $27.5^{\mathrm{b}}$ & $29.9^{\mathrm{b}}$ & $88.4^{\mathrm{b}}$ & $88.4^{\mathrm{b}}$ & $79.1^{\mathrm{b}}$ & $79.1^{\mathrm{b}}$ \\
\hline
\end{tabular}

${ }_{\mathrm{a}, \mathrm{b}}$ Values within a column with different superscripts differ $(P \leq 0.05)$.

${ }^{1} \mathrm{AI}=$ either timed AI or AI at detected estrus with conventional semen following a synchronization protocol; ET-V = embryo transfer of vitrified embryos produced in vitro with sex-sorted semen following a synchronization protocol; ET-F = embryo transfer of fresh embryos produced in vitro with sex-sorted semen following a synchronization protocol.

${ }^{2}$ Percent of calves that were heifers born dead and alive.

${ }^{3}$ Percent of live calves that were live heifers born.

${ }^{4} \mathrm{~A}$ cow was considered to have a synchronized estrous cycle if progesterone concentration was $<1.0 \mathrm{ng} / \mathrm{mL}$ at anticipated ovulation $(\mathrm{d} 0)$ and a visible corpus luteum was present on $\mathrm{d} 7$. 
pregnancy rates achieved with fresh embryos compared with AI during the summer.

One strategy to alter the gender ratio of calves following IVP embryo transfer is to use sex-sorted semen. Studies evaluating pregnancy rates following the transfer of IVP embryos fertilized with sex-sorted semen are limited. In a study by Xu et al. (2006), pregnancy rates obtained following the transfer of vitrified IVP embryos produced with sex-sorted semen were similar to those obtained following the transfer of vitrified IVP embryos produced with non-sorted semen. The present study is the first to indicate that the transfer of fresh IVP embryos produced with sex-sorted semen can be used to increase the percentage of cows that become pregnant and calve following summer AI. Although no embryos transferred in the present study were produced using non-sorted semen, results are consistent with 2 previous studies in which the transfer of fresh IVP embryos produced with non-sorted semen improved fertility in the summer compared with TAI (Ambrose et al., 1999; Al-Katanani et al., 2002). In fact, the proportion of synchronized cows pregnant at d 40 after transfer of a fresh IVP embryo produced with sex-sorted semen $(45.5 \%)$ is greater than the pregnancy rate achieved at d 45 to $52(17.3 \%)$ as reported by Ambrose et al. (1999) and at d $45(26.7 \%)$ as reported by Al-Katanani et al. (2002) using IVP embryos produced with non-sorted semen. The higher pregnancy rates seen in the present study could be because of differences in climatic conditions and severity of heat stress between studies, because of improvement in culture conditions with the use of BBH7 (Block et al., 2010) or other improvements in the system for embryo production and transfer.

As expected, the transfer of IVP embryos fertilized with sex-sorted semen increased the percentage of cows that gave birth to a heifer compared with cows AI with non-sorted semen. This was consistent whether analyses included all calves born or just live calves and regardless of whether the embryos were transferred fresh or following vitrification (Table 3). The overall gender ratio in the present study for the embryo groups was $84.3 \%$ female, which is comparable to previous studies in which the gender ratio following transfer of IVP embryos fertilized with sex-sorted semen has ranged from 85 to $96.5 \%$ (Wilson et al., 2005; Xu et al., 2006; Loureiro et al., 2009). This is also consistent with previously reported data in which AI with conventional semen was compared with AI with female sex-sorted semen in lactating dairy cows and the female gender ratio for percentage of calves born that were heifers was 90\% (DeJarnette et al., 2009; Norman et al., 2010) Thus, use of sex-sorted semen to produce IVP embryos is an effective way to overcome the skewed male gender ratio typically observed for IVP embryos produced with non-sorted semen and also dramatically increase the percentage of cows giving birth to a live heifer compared with using AI.

It is well known that IVP embryos are sensitive to cryopreservation (Al-Katanani et al., 2002; Lazzari et al., 2002; Rizos et al., 2002). In 3 previous studies, the transfer of either conventionally frozen (Ambrose et al., 1999; Drost et al., 1999) or vitrified (Al-Katanani et al., 2002) IVP embryos did not improve fertility of lactating cows during the summer compared with AI. In the present study, embryos were cultured in $\mathrm{BBH} 7$, a culture medium that was developed to improve embryo development and survival following cryopreservation. Both the results reported herein and in a recently published study (Block et al., 2010) indicate that embryos cultured in BBH7 had increased cryosurvival following vitrification compared with earlier reported results, where vitrified embryos had significantly lower fertility than that from conventional AI (Al-Katanani et al., 2002). However, results reported herein and in a recently published study (Block et al., 2010) illustrate that vitrified embryos still have decreased fertility compared with IVP fresh embryos, yet the fertility is similar to that of conventional AI. Among cows that were considered synchronized, a tendency existed $(P=$ 0.10 ) for the percentage of cows pregnant at d $40 \pm 7$ of gestation to be greater for the ET-V than the AI group, but no difference existed in the percentage of cows pregnant at d $97 \pm 7$ of gestation and no difference was observed in the percentage of cows calving between the ET-V and AI groups (Tables 2 and 3). These results indicate that the culture of embryos in $\mathrm{BBH} 7$ does not improve the cryotolerance of IVP embryos sufficiently to improve fertility during the summer in lactating cows. This finding is consistent with the findings of Block and colleagues (2010), in which pregnancy rates in lactating dairy cows, following the transfer of vitrified embryos cultured in $\mathrm{BBH} 7$, were similar to those obtained following TAI. Nonetheless, the percentage of cows pregnant was greater with ET-V than that in previously reported studies using vitrified or frozen IVP embryos versus conventional AI during summer (Ambrose et al., 1999; Al-Katanani et al., 2002)

The percentage of cows that were successfully synchronized based on plasma concentrations of $\mathrm{P}_{4}$ on $\mathrm{d}$ 0 and the presence of a visible CL on $\mathrm{d} 7$ in this study was $69.7 \%$, which is consistent with the 65.8 to $76.2 \%$ synchronization rates reported previously for studies involving heat-stressed, lactating dairy cows (Ambrose et al., 1999; Al-Katanani et al., 2002; Block et al., 2003). The percentage of synchronized cows was higher at farm 2 than farm 1 (Table 1). One possible explanation for this difference is that at farm 1 , all cows subjected to the synchronization program were enrolled in the study 
and no estrus detection took place, whereas at farm 2 , cows were subjected to a synchronization program but only those cows that were observed in estrus 48 to $72 \mathrm{~h}$ after $\mathrm{PGF}_{2 \alpha}$ treatment were enrolled in the experiment.

The percentage of cows pregnant at $\mathrm{d} 40 \pm 7$ and $\mathrm{d}$ $90 \pm 7$ and the percentage of cows calving were higher for farm 2 than farm 1. It is likely that fertility at farm 2 was higher because more primiparous cows were enrolled and, as stated above, only those cows that were observed in estrus were used. Also, at farm 2, confounding may have occurred because cows were enrolled on $\mathrm{d}$ 2 for AI and d 3 for ET because of logistical constraints at the farm and with embryo production and transfer. However, no treatment $\times$ farm interactions existed for any effects observed.

In conclusion, results indicate that the fertility of heat-stressed, lactating cows can be increased following the transfer of fresh IVP embryos produced using sexsorted semen. In addition, the use of embryo transfer with IVP embryos produced using sex-sorted semen during the summer is an effective method for increasing the proportion of live heifer calves born. The transfer of vitrified embryos, produced following culture in $\mathrm{BBH} 7$ medium, did not improve fertility during the summer over that using AI. Continued research efforts are necessary to improve the efficacy of using cryopreserved IVP embryos to improve fertility during the summer in lactating cows.

\section{ACKNOWLEDGMENTS}

The authors thank Wildcat (Frank Volleman; Gustine, TX) and MX7 (Wayne Moorman; Comanche, TX) dairies and their respective staff members for allowing use of their facilities and their assistance with field work for this project. The authors also thank E.I. Medical Imaging (Loveland, CO) for use of their Ibex Pro ultrasound and ABF Packing (Dublin, TX) for their assistance in the collection of ovaries. This project was supported by Agriculture and Food Research Initiative Competitive Grant no. 2010-85122-20623 from the USDA National Institute of Food and Agriculture and OvaTech, LLC (Gainesville, FL).

\section{REFERENCES}

Al-Katanani, Y. M., M. Drost, R. L. Monson, J. J. Rutledge, C. E. Krininger III, J. Block, W. W. Thatcher, and P. J. Hansen. 2002. Pregnancy rates following timed embryo transfer with fresh or vitrified in vitro produced embryos in lactating dairy cows under heat stress conditions. Theriogenology 58:171-182.

Ambrose, D. J., T. Govindarajan, and L. A. Goonewardene. 2006. Conception rate and pregnancy loss rate in lactating Holstein cows of a single herd following timed insemination or insemination at detected estrus. J. Dairy Sci. 89(Suppl. 1):213-214.
Ambrose, J. D., M. Drost, R. L. Monson, J. J. Rutledge, M. L. Leibfried-Rutledge, M.-J. Thatcher, T. Kassa, M. Binelli, P. J. Hansen, P. J. Chenoweth, and W. W. Thatcher. 1999. Efficacy of timed embryo transfer with fresh and frozen in vitro produced embryos to increase pregnancy rates in heat-stressed cattle. J. Dairy Sci. 82:2369-2376.

Berman, A. 2005. Estimates of heat stress relief needs for Holstein dairy cows. J. Anim. Sci. 83:1377-1384.

Berman, A., Y. Folman, M. Kaim, M. Mamen, Z. Herz, D. Wolfenson, A. Arieli, and Y. Graber. 1985. Upper critical temperatures and forced ventilation effects for high-yielding dairy cows in a subtropical climate. J. Dairy Sci. 68:1488-1495.

Block, J., L. Bonilla, and P. J. Hansen. 2010. Efficacy of in vitro embryo transfer in lactating dairy cows using fresh or vitrified embryos produced in a novel embryo culture medium. J. Dairy Sci. 93:5234-5242.

Block, J., M. Drost, R. L. Monson, J. J. Rutledge, R. M. Rivera, F. F. Paula-Lopes, O. M. Ocon, C. E. Krininger III, J. Liu, and P. J. Hansen. 2003. Use of insulin-like growth factor-I during embryo culture and treatment of recipients with gonadotropin-releasing hormone to increase pregnancy rates following the transfer of in vitro-produced embryos to heat-stressed, lactating cows. J. Anim. Sci. 81:1590-1602.

Block, J., and P. J. Hansen. 2007. Interaction between season and culture with insulin-like growth factor-1 on survival of in vitro produced embryos following transfer to lactating dairy cows. Theriogenology 67:1518-1529.

Brusveen, D. J., A. H. Souza, and M. C. Wiltbank. 2009. Effects of additional prostaglandin $\mathrm{F}_{2 \alpha}$ and estradiol-17 $\beta$ during Ovsynch in lactating dairy cows. J. Dairy Sci. 92:1412-1422.

DeJarnette, J. M., R. L. Nebel, and C. E. Marshall. 2009. Evaluating the success of sex-sorted semen in US dairy herds from on farm records. Theriogenology 71:49-58.

Demetrio, D. G., R. M. Santos, C. G. Demetrio, and J. L. Vasconcelos. 2007. Factors affecting conception rates following artificial insemination or embryo transfer in lactating Holstein cows. J. Dairy Sci. 90:5073-5082

Dikmen, S., and P. J. Hansen. 2009. Is the temperature-humidity index the best indicator of heat stress in lactating dairy cows in a subtropical environment? J. Dairy Sci. 92:109-116.

Drost, M., J. D. Ambrose, M.-J. Thatcher, C. K. Cantrell, K. E. Wolfsdorf, J. F. Hasler, and W. W. Thatcher. 1999. Conception rates after artificial insemination or embryo transfer in lactating dairy cows during summer in Florida. Theriogenology 52:1161-1167.

Ferguson, J. D., D. T. Galligan, and N. Thomsen. 1994. Principal descriptors of body condition score in Holstein cows. J. Dairy Sci. 77:2695-2703.

Hansen, P. J. 1997. Effects of environment on bovine reproduction. Pages 403-415 in Current Therapy in Large Animal Theriogenology. R. S. Youngquist, ed. WB Saunders, Philadelphia, PA.

Hansen, P. J. 2007. Exploitation of genetic and physiological determinants of embryonic resistance to elevated temperature to improve embryonic survival in dairy cattle during heat stress. Theriogenology 68:S242-S249.

Hasler, J. F. 2000. In vitro culture of bovine embryos in Ménézo's B2 medium with or without coculture and serum: The normalcy of pregnancies and calves resulting from transferred embryos. Anim. Reprod. Sci. 60-61:81-91.

Lazzari, G., C. Wrenzycki, D. Herrmann, R. Duchi, T. Kruip, H. Niemann, and C. Galli. 2002. Cellular and molecular deviations in bovine in vitro-produced embryos are related to the large offspring syndrome. Biol. Reprod. 67:767-775.

Loureiro, B., L. Bonilla, J. Block, J. M. Fear, A. Q. Bonilla, and P. J. Hansen. 2009. Colony-stimulating factor 2 (CSF-2) improves development and posttransfer survival of bovine embryos produced in vitro. Endocrinology 150:5046-5054.

Norman, H. D., J. L. Hutchison, and R. H. Miller. 2010. Use of sexed semen and its effect on conception rate, calf sex, dystocia, and stillbirth of Holsteins in the United States. J. Dairy Sci. 93:38803890 . 
NRC. 1971. A Guide to Environmental Research on Animals. Natl. Acad. Sci., Washington, DC.

Parrish, J. J., J. L. Susko-Parrish, E. S. Critser, W. H. Eyestone, and N. L. First. 1986. Bovine in vitro fertilization with frozen-thawed semen. Theriogenology 25:591-600.

Rizos, D., F. Ward, P. Duffy, M. P. Boland, and P. Lonergan. 2002. Consequences of bovine oocyte maturation, fertilization or early embryo development in vitro versus in vivo: Implications for blastocyst yield and blastocyst quality. Mol. Reprod. Dev. 61:234248.

Robertson, I., and R. E. Nelson. 1998. Certification and identification of the embryo. Pages 103-116 in Manual of the International Embryo Transfer Society. 3rd ed. S. E. Seidel and D. A. Stringfellow, ed. International Embryo Transfer Society (IETS), Champaign, IL.

Sartori, R., R. Sartor-Bergfelt, S. A. Mertens, J. N. Guenther, J. J. Parrish, and M. C. Wiltbank. 2002. Fertilization and early embryonic development in heifers and lactating cows in summer and lactating and dry cows in winter. J. Dairy Sci. 85:2803-2812.

SAS Institute. 2008. Statistical Analysis Software. Version 9.2. SAS Inst. Inc., Cary, NC.

Stevenson, J. S., Y. Kobayashi, and K. E. Thompson. 1999. Reproductive performance of dairy cows in various programmed breeding systems including OvSynch and combinations of gonadotropin-releasing hormone and prostaglandin $\mathrm{F}_{2 \alpha}$. J. Dairy Sci. 82:506-515.

Udomprasert, P., and N. B. Williamson. 1987. Seasonal influences on conception efficiency in Minnesota dairy herds. Theriogenology $28: 323-336$.
Umphrey, J. E., B. R. Moss, C. J. Wilcox, and H. H. Van Horn. 2001. Interrelationships in lactating Holsteins of rectal and skin temperatures, milk yield and composition, dry matter intake, body weight, and feed efficiency in summer in Alabama. J. Dairy Sci. 84:2680-2685.

Vajta, G., P. Holm, M. Kuwayama, P. J. Booth, H. Jacobsen, T. Greve, and H. Callesen. 1998. Open pulled straw (OPS) vitrification: A new way to reduce cryoinjuries of bovine ova and embryos. Mol. Reprod. Dev. 51:53-58.

van Wagtendonk-de Leeuw, A. M., B. J. G. Aerts, and J. H. G. den Daas. 1998. Abnormal offspring following in vitro production of bovine embryos: A field study. Theriogenology 49:883-894.

Wilson, R. D., K. A. Weigel, P. M. Fricke, J. J. Rutledge, L. M. Leibfried-Rutledge, D. L. Matthews, and V. R. Schutzkus. 2005. In vitro production of Holstein embryos using sex-sorted sperm and oocytes from selected cull cows. J. Dairy Sci. 88:776-782.

Wolfenson, D., Z. Roth, and R. Meidan. 2000. Impaired reproduction in heat-stressed cattle: Basic and applied aspects. Anim. Reprod. Sci. 60-61:535-547.

Xu, J., Z. Guo, L. Su, T. L. Nedambale, J. Zhang, J. Schenk, J. F. Moreno, A. Dinnyés, W. Ji, X. C. Tian, X. Yang, and F. Du. 2006. Developmental potential of vitrified Holstein cattle embryos fertilized in vitro with sex-sorted sperm. J. Dairy Sci. 89:2510-2518. 